\title{
A Review on the Attribution Theory in the Social Psychology
}

\author{
Sodabeh Mirsadeghi \\ Department of Psychology, UPM, Malaysia
}

\begin{abstract}
Attribution includes the process that is used by people to link the underlying causes of the events. Social psychologists in analyzing attribution case, as with many other issues, do not have full consensus and they analysis and study it from different perspectives. That is different theories have been imposed in this case. In this article we will cover some of the most convincing attribution theory.
\end{abstract}

Keywords: Attribution, Social, Psychology, Theory

\section{Introduction}

Recent researches base on the theory of Attribution emphasis in various fields, including curriculum development, job performance, employee productivity, job satisfaction, athletic achievements, perversion, crime, alcoholism, divorce, and so. Fairly comprehensive reviews of the literature related to the Attribution took overall by Michela and Ross and Fletcher. Similarly, Rjeski and Brawley conducted interesting review on archival research in sport. Koski combined attribution theory with labeling theory and apply it's about perception and treatment of juvenile delinquents by using juvenile institution responsible staff. He believed that attribution given by the staff cover predictions of the main consequences of the Attribution for the behavior of young offenders, and the community includes institutions. Because these attributions determine the extent to which an individual has access to recreational opportunities and when the focus is discharged. In this study, the role of age, sex and race were not predictors and it seemed Juvenile offenders under the long-term behavior of the originals. Attribution theory in social psychology focuses on a central theme, namely how and under what conditions can determine whether a person or a situation attribution has been successful of the behavior in compare with the others, but Ross and Fletcher believe that it is not noticed all the evaluations of other behaviors that have occurred since then.

\section{Simple psychology attribution theory}

The oldest attribution is observed in the works of Fritz Hayder theory formulation. In his opinion, most people, who are new to psychologists, trying to understand the behavior of others to make the world more predictable. According Hayder, most people apply on this explain one of the following:

A - They may have assumed situational factors such as economic factors that affect the behavior of another person or social pressures. (Situational attribution)

B - They may imagine that the behavior was unintentional and accidental and probably will not happen in the future. (Situational attribution).

$\mathrm{C}$ - The third explanation is this that the person has developed their own personal behavior traits. (Personal records).

Hayder believes that the personal attribution will obvious when environment provide a variety of behaviors. When about one person's personal Attribution were deduced these Attribution may be used to predict behavior.

\section{Jones and Davis theory correspond to deduced Attribution}

Jones and Davis have focused their attention on the consequences of behavior as a basis Attribution. According to their idea determine the effects of Attribution process in a given situation of each possible answer. Unusual consequences generous give us insights about the behavioral tendencies. As the name implies theory, personal traits understanding about when behavior is a manifestation of the supposed traits, they are matched with. In simpler words, the theory predicts that People are trying to elicit an action whether the operation of a feature (attribute) matches the person's permanent or not. A person who displays aggressive behavior Is Beastliest? A person who gives money to charity individuals are altruists? To answer such questions, people do inference based on three factors.

The first factor is the degree of one's choice. Behaviors that are freely chosen are better to show private Attribution from the behaviors that may be imposed. In the experiment Jones and Harris, the students wrote an essay against Fidel Castro. Half the participants were told that the position he has chosen freely and the other half says his teachers have been appointed to the position. Then participants were asked the real attitude of the students to guess participants' behavior and attitudes of the student when he was the right choice saw more respect until there was no choice. 
The second factor is the rate of expected behavior that leads people to understanding trend. Behaviors that are far from the norm, tell us something more about the person from the normal behaviors that are part of a social role or be expected under the circumstances. Way people think they know more from the man's character who wears the clothes punk or rap or citizenship that evasion from give tax to people who dress in ordinary clothes and they pay taxes on time.

The third factor that people consider is the inferred orientation impacts or consequences of one's behavior. Several actions have the desired returns a person's inner motivations and actions clearly desirable to produce a single output or return are not acceptable. For example, it is possible we cannot certainly say that why a person whose job is enjoyable and has a high income and is located in a lovely location. Job that has three good returns and each of them are sufficient to explain such behavior. Conversely, it is an interesting in the case, that's why this job is boring or has low income we feel more confident in the attribution orientation.

\section{Harold change theory}

Corresponding analytic theory describes that how people try to determine personal characteristics of a person from one part of the evidence his behavior. But treat can be attributing not only to individual agents but it can also be attribution of the situation. How is this distinction? At this point Harold is Agrees with Hayder that in general public act as well as scientists. They maybe do comparisons and based on this comparison and think similar the results simulation experimental think. According to the Harold attribution public do it's attribution base on the pace of change that says the reason for the behavior that occur the agent must be present and when the behavior does not occur then the agent is not present.

Three types of information are important to this theory:

Unanimous: Does someone have the same behavior in the same situation?

Distinguishing: whether the behavior is the same for other drivers?

Stability: does a person have same action against the same triggers?

\section{Shaver hybrid Attribution Theory}

Shaver combined three main Attribution theories and constructs a general theory. His formulated the theory of attribution based on three assumptions about human nature. First, the behavior does not occur randomly, but organized therefore, are predictable. Second, people the desire to understand, to explain and predict the behavior of others. If this prediction is done correctly allows the person to more effectively cope through their environment. The third assumption, people visible behaviors give credible information about their underlying causes especially about character and personal traits (the latter assumption is questionable. Because studies suggest that behavior does not always reflect a person's attitude)

\section{Weiner further classification of Attribution}

The general theory of Harold tells us that what kind of information cause personal or situational attribution, but between these two types of attribution many others attributions exist. For descriptions of other Attribution, Bernard Weiner assumes a three-dimensional classification that explains the attribution of success and failure. According to Weiner, People attribute behavior not only the factor (1) intrinsic (personal) or external (situational) but also they attribution to the factors that (2) stable or unstable. We have tried to evaluate success or failure of an exercise, a test score, the failure of a commodities market, or unemployment alone, our explanations often are among eight types of Attribution that may be obtained by the combination of the three dimensions. When people describe their own performance, different types of attribution can have different motivational and emotional consequences for them. After the victory we have better feel to ourselves and others rather than failure. But the Attribution are made has equally important of its own consequences.

According to Weiner, interior or exterior location of attribution related emotion of self-esteem with our performance that affected. People are proud after a victory and after fracture embarrassed. So when related this success to internal factors (such as their talent and effort), they have pride, And when attribute their failure to external factors (characteristics of the task or luck), They feel shame. Conversely, this is the stability of an attribution which will determine future expectations. When people attribute success or failure to other factor do not change from one moment to another moment. According to their performance, their hopes are high and low when attribute to the outcomes to unstable factors (luck or effort). Hoping they will yield relatively unchanged. Finally, the ability to control a stimulated attribution cause to pay attention what Weiner calls it social emotions. When people attribute negative returns to the factors that control the person factors are uncontrolled will be angry.

\section{Attributions to our self}


One of the more interesting hypotheses in attribution theory is this that people perceive their internal states as same way to others. This notion stems from the public's thoughts that the emotions, attitudes, traits and abilities often ambiguous to us and it is unclear and expedition., Which characterized have his overt behaviors and environmental factors that surround us. We understand, according to this approach, our self-perception, perception of others as well as to search for cause and affect us. We can use the principle of shared responsibility for discounts on causes, if we feel Powerful external forces pushing us to behave ourselves. We suppose one more oriented Attribution a situation in which Attribution reach in the absence of external forces, but obviously this approach leads to a considerable amount of research.

\section{Attitudes}

Psychologists assume that people tend to seek their views through introspection it is mean that they do by reviewing the various cognitive and emotional that lies in their consciousness. Bam, contrary to this belief statements that attitude that we're only getting a very limited and vague internal, Just in case we do not have direct access to internal and because it is our attitudes by observing our behavior should be evident to deduce. We conduct ourselves in a situation when no external forces are strong. We will see, we thought the views expressed are real and a set of internal attribution. Conversely, when we are strong forces pushing outward to do something as we put it in the mail so we understand that we are the ones that are caused by external factors. In other words, we observe their behavior in different environments, with external pressures; we obtain information about their attitudes not by introspection to understand what we are feeling. Bam is not a claim that people do not always have the internal attribution, but he is claiming that people rely on external for his overt behavior and the conditions under which behaviors occur so that they understand their true attitudes.

\section{Conclusion}

When people try to describe their performance, different types of attribution can have different motivational and emotional consequences for them. A person can determine how and under what conditions the personal attribution or situational behavior of others has been successful. Ross and Fletcher conclude that there is no reason to assume that people are always has in the mind and even the curious what is the cause of their behavior with others. This explained by the significant reduction of process attribution it refers only to some of the limitations of this theory.

\section{References}

[1] Anderson ;(2001), Symbolic Psychologic: A model of attiludinal Cognition. Behavioral Science;3,1 -13

[2] Arkin, R.M, Gleason, J.M, and Johnston, S, (1976), Effects of perceived choice, expected outcome, and observed outcome of an action on the causal attribution of actors. Journal of Experimental and Social Psychology, 12, 151-158.

[3] Bechara; (2000), A relational obligations approach to the foot-in-the- mouth effect. Journal of Applied Social Psychology,24,546-556

[4] Barown, J. (2000), An introduction to motivation, New York, vonnostrand, vol, 31.

[5] Baker, H, (2003), Introduction to Mental Health in the Exceptional Children. NewYork: The Macmillan Company.

[6] Bar-On, R. (2000). The Emotional Quotient Inventory (EQ-i): Technical Manual. Toronto, Canada: Multi-Health Systems, Inc. 